\title{
Reinforcing Teaching Strategies with Demonstrational Videos in Dental Education
}

\author{
Haydar MMi*, Tan $\mathrm{SY}^{2}$, Melissa $\mathrm{WLZ}^{2}$, Yee $\mathrm{LF}^{2}$, Chong $\mathrm{PJ}^{2}$, Tan $\mathrm{PK}^{2}$ and Sum $\mathrm{CY}^{2}$ \\ ${ }^{1}$ Lecturer, Faculty of Dentistry, SEGi University, Malaysia \\ ${ }^{2}$ BDS Student, Faculty of Dentistry, SEGi University, Malaysia
}

*Corresponding author: Haydar Majeed Mahdey, Faculty of Dentistry, SEGi University, 9 Jalan Teknologi, Taman Sains Selangor, PJU 5, Kota Damansara, 47810 Petaling Jaya, Selangor, Malaysia.

Received Date: August 17, 2018

Published Date: September 06,2018

\section{Abstract \\ Introduction: Blended learning is the trending concept in current educational system including the field of dentistry where traditional teachings are combined with online resources such as demonstrational videos etc.}

Aims and Objectives: To assess whether demonstrational videos help enhance dental student's confidence, knowledge and technique during local anesthesia injection.

Methods: Fifty dental students of year 3 (B.D.S.) of SEGi University were randomly allocated into two groups. Both groups were given live demonstration of the posterior superior alveolar (PSA) nerve injection technique. In addition, the test group received additional demonstrational video to watch. Then both the groups were made to inject on each other. Two oral surgeons assessed both the groups individually on some fixed criteria for injection technique. The data were collected and analyzed using SPSS version 22, mean values and percentages were compared between 2 groups using independent sample t-test and Chi-square test respectively. $\mathrm{p}<0.05$ was considered statistically significant.

Results: The mean score for injection technique was 1.4038 in control group and 1.6957 in the test group with $p=0.004$. In other aspects of this study, there was no significant difference found.

Conclusion: Demonstrational videos helped improve injection technique among dental undergraduates.

Keywords: Teaching; Visual learning; Dentistry; Dental; Demonstrating tools

\section{Introduction}

In today's digital era, education systems have been evolved from the traditional teaching method into learning through demonstrational videos that can be obtained readily on the Internet provided by various social networking platform such as Facebook, Twitter, YouTube and many more [1]. These websites play a major role in education due to its convenience and its distribution capacity [1]. Furthermore, most dental students are very equipped with modern day technology such as smart phones, laptops, tablets and WIFI connection throughout the campus. The goal of this research is to compare the effectiveness and the benefits of demonstrational videos in addition to live demonstrations carried out by lecturers to dental students in SEGi University. After these outcomes are collected and examined, this study will investigate how these data will affect Faculty of Dentistry in SEGi University's professionalism curricula and ask whether it is good to consider implementing demonstrational videos along with live demonstrations by lecturers to the dental students [2]. The main aim of this study is to assess whether demonstrational videos help enhance dental student's confidence, knowledge and technique during local anesthesia injection. To achieve our aim, this study been planned to investigate the effectiveness of demonstrational videos in enhancing dental student's performance in local anesthesia injection as it compares student's confidence and attitude before and after watching the demonstrational video and finally to investigate the probability pf implementing demonstrational videos in addition to regular dental education in the Faculty of Dentistry, SEGi University.

According to Donald et al. [3] the findings from the study suggest that students who were exposed with video had a significantly better cognitive and affective learning outcomes than paper in an introductory course on public healthy dentistry. However, there 
were no findings with the effectiveness of videos in adjunct to paper. Sourev et al. [4] has also reported that the use of videos that can be found on various social media platform do help dentist in expanding their knowledge and learning. A study from Badr A et al. [2] have compared the addition of videos to normal day lecture with just lectures among year 3 dental students showed improvement in student's learning outcomes and that videos should be incorporated to assist with lectures. Also, findings reported by Viswasom AA et al. [5] showed dissatisfaction with learning through demonstrational videos alone. This is because that students from his study found that some familiar and productive learning strategies, such as marking books became impossible or very difficult to implement when studying with video alone and also that rewind and forward of the video were both very new and difficult to implement as desired by the students as students during that time were not very accustomed to modern technology as compared to students from this era.

\section{Methodology}

The research group students have made educational videos for this study to demonstrate the posterior superior alveolar (PSA) never injection. The students had been supervised and validated by their lecturer supervisor. (Figures 1-3). A total of 50 (year 3) dental students of SEGi University were randomly allocated into two groups, which is Group A (25students) and Group B (25students). A consent form had been signed by the study subjects before the start of this study.

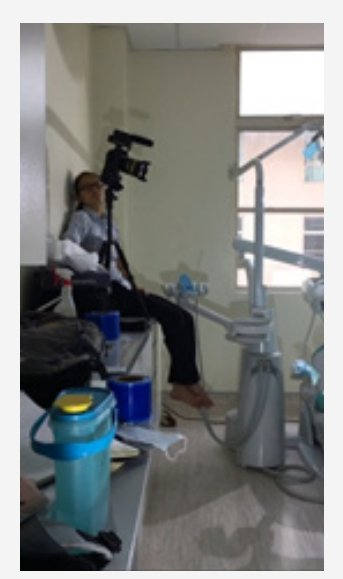

Figure 1: The research group students while they were shooting the educational videos.

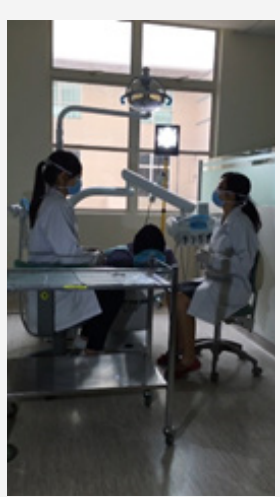

Figure 2: The research group students while they were shooting the educational videos.

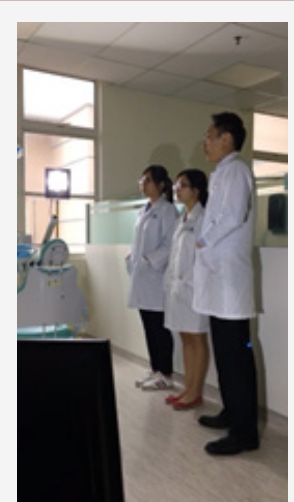

Figure 3: The research group students while they were shooting the educational videos.

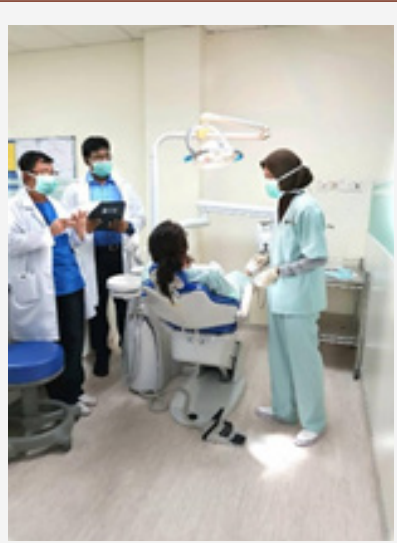

Figure 4: 2 oral surgeon were evaluating and assessing the research subjects.

Both groups were given live demonstration of the posterior superior alveolar (PSA) nerve injection technique and asked to perform the injection technique on each other separately for the first time. 2 oral surgery specialists had been evaluated and assessed the student's performance (Figure 4) based on a set mark scheme. After all the sample students have been performed their first-time injection technique, questionnaires were handled to the students. The questionnaires were answered anonymously and no personal data except for gender of the test subjects that been collected.

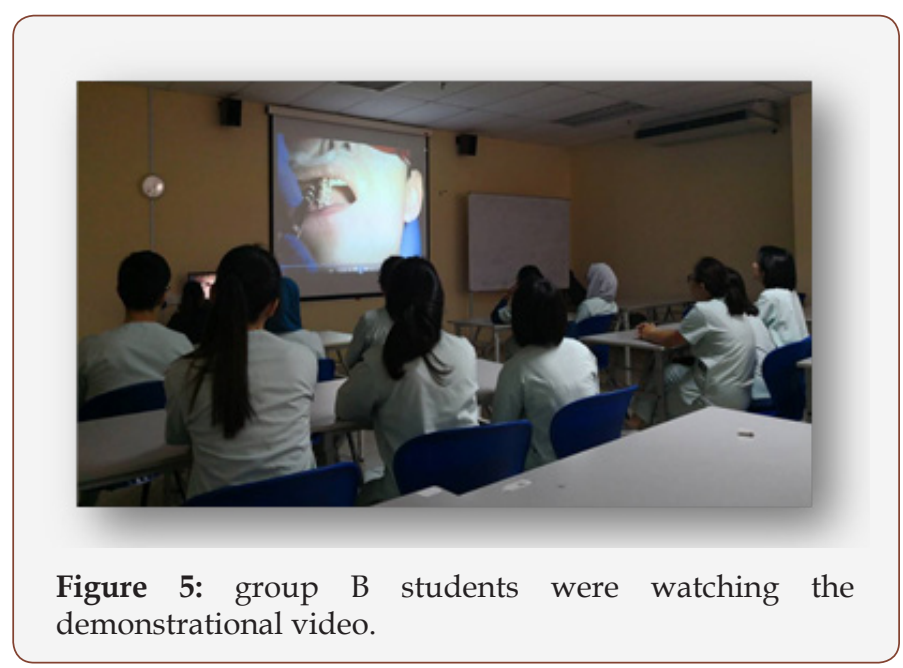

Before they perform the injection technique on the second time, Group B students had watched the demonstration video 
on PSA injection technique (Figure 5) and both groups asked to perform the PSA injection on each other again separately (second time). 2 oral surgery specialists had been evaluated and assessed the student's performances again. After all the sample students had performed all injections, questionnaires were given to them once again. Data been collected and analyzed using SPSS version 22. Chi Square test and student's T-test were used. $\mathrm{p}<0.05$ was considered significant (Figure 6)

\begin{tabular}{|l|l|l|l|l|l|l|}
\hline \multicolumn{2}{|c|}{ Questions } & \multicolumn{3}{c|}{ Group A } & \multicolumn{3}{c|}{ Group B } \\
\cline { 2 - 6 } & Agree & Disagree & Uncertain & Agree & Disagree & Uncertain \\
\hline $\begin{array}{l}\text { 1. The live demonstration on PSA nerve block } \\
\text { injection technique is clear and easily understood }\end{array}$ & $92.30 \%$ & $3.80 \%$ & $3.80 \%$ & $92.30 \%$ & $4.20 \%$ & $0 \%$ \\
\hline $\begin{array}{l}\text { 2. The live demonstration clears your doubts } \\
\text { regarding how PSA nerve block is performed. }\end{array}$ & $84.60 \%$ & $3.80 \%$ & $11.50 \%$ & $87.50 \%$ & $4.20 \%$ & $4.20 \%$ \\
\hline $\begin{array}{l}\text { 3. After viewing the live demonstration, you are } \\
\text { more confident to perform PSA nerve block on a } \\
\text { patient. }\end{array}$ & $69.20 \%$ & $3.80 \%$ & $26.90 \%$ & $87.50 \%$ & $4.20 \%$ & $4.20 \%$ \\
\hline $\begin{array}{l}\text { 4. You are satisfied with your performance in } \\
\text { injecting PSA nerve block. }\end{array}$ & $53.90 \%$ & $11.50 \%$ & $34.60 \%$ & $66.70 \%$ & $4.20 \%$ & $25 \%$ \\
\hline $\begin{array}{l}\text { 5. You are able to remember the PSA nerve block } \\
\text { technique (patient position, point of needle }\end{array}$ & $84.60 \%$ & $3.80 \%$ & $11.50 \%$ & $87.50 \%$ & $0 \%$ & $8.30 \%$ \\
\hline $\begin{array}{l}\text { insertion) better after viewing the live } \\
\text { demonstration. }\end{array}$ & & & & & & \\
\hline $\begin{array}{l}\text { 6. This method of demonstration is beneficial in } \\
\text { learning injection technique. }\end{array}$ & $92.30 \%$ & $3.80 \%$ & $7.70 \%$ & $87.50 \%$ & $0 \%$ & $8.30 \%$ \\
\hline $\begin{array}{l}\text { 7.This live demonstration method should be } \\
\text { included as a teaching method in addition to the } \\
\text { lecture on injection technique. }\end{array}$ & $92.30 \%$ & $3.80 \%$ & $3.80 \%$ & $91.70 \%$ & $0 \%$ & $4.20 \%$ \\
\hline
\end{tabular}

Figure 6: Answer results for both Group A \& B questionnaires answers.

\section{Results}

As this study had compared the questionnaire responses between group A and group B, the group with both live and video demo feels more confident in performing PSA nerve block as well as feel more satisfied with their nerve block performance compared to the group with live demo alone (Figure 6). Based on the evaluation scores by the assessors on both group's performance, it was found that the group with both live and video demonstration did significantly better than the group with only live demo, with the $p$ value of 0.004 (Chart 1$)$.

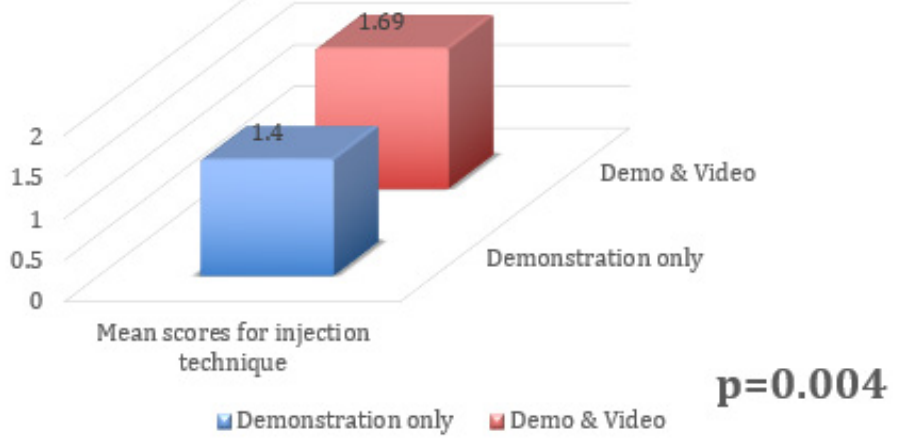

Chart 1: Comparison of mean scores as given by assessors for performing the block between two groups.

\section{Discussion}

The samples of this this study is a year 3 dental students, as it was their first exposure to clinical years and have no prior experience in injecting PSA nerve block. It is known that with the growing use of technology gadgets such as smartphones and laptop, the Internet is the preferable method in attaining information. This 
was in consonance with our questionnaire responds when the students agreed that demonstrational videos are easily available over the internet and assisted them in better understanding of the topic.

However, when this study compared between the effectiveness of live demonstration and video demonstration, it been found that the group with an addition of demonstrational video did significantly better in their injection technique. $(p=0.004)$ The same group also felt more confidence in performing the PSA nerve block. The probable reason for this could be attributed to the enhanced and clearer view of the injection technique from the video as well as the ability to playback the video, which live demonstration, could not provide. The outcome of our study has similar findings as previous studies by Al-Jandan BA et al. [2], Donald et al. [3] and Sourav et al. [4].

Although video demonstration is of importance, a study by Avner et al. [5] found that learning through demonstrational videos alone showed dissatisfaction in effectiveness in learning. The result may be caused by the lack of interaction whereby the students could not clarify their doubts as well as this study's sample was too small. Therefore, both live and video demonstration should be included in the learning curriculum on top of lectures as it brings better visualization and understanding of the technique when viewing it during demonstration compared to just learning the theory from the lecture and pictures from textbooks. This is resonant with the findings from our questionnaire where majority of students strongly agree with these teaching methods in conjunction with lectures.

\section{Conclusion}

Demonstrational videos as an adjunct to live demonstration enhanced the injection technique and confidence among the Year 3 dental students. Demonstrational videos should be used handin-hand with conventional teaching methods in order to attain superior teaching strategy.

\section{Recommendations}

For future studies, the study should also include the inferior alveolar nerve (IAN) block as it is more technique sensitive than PSA nerve block and comparison between both nerve blocks could be done. Studies could also be done in different branches of dentistry such as Periodontics with periodontal surgery as well as the different suturing techniques and even in conservative dentistry.

\section{Limitations}

One clear limitation of the study is that there is insufficient time to carry out more injection techniques, for example inferior alveolar nerve block, long buccal nerve block, lingual nerve block and mental nerve block. And due to first time of exposure of live subjects to posterior superior alveolar nerve block injection technique, some subjects may experience some degree of nervousness which may influence their performances.

\section{Conflict of Interests}

The authors declare no conflicts of interest.

\section{Acknowledgements}

Authors would like to acknowledge Associate Professor Dr. Datuk Khairiyah Abd Muttalib, Dr. Myint Wei and Dr. Arun Paul for their support and contribution for this study.

\section{References}

1. Oakley M, Spallek H (2012) Social Media in Dental Education: A Call for Research and Action. J Dent Educ 76(3): 279-287.

2. Badr A Al-Jandan, Imran Farooq, Soban Oadir Khan (2015) Students perspectives on the relevance of internet-based educational videos in dental education. Journal of Taibah University Medical Sciences 10(3): 288-292.

3. Fat MJ, Doja A, Barrowman N, Sell E (2011) YouTube videos as a teaching tool and patient resource for infantile spasms. J Child Neurol 26(7): 804809.

4. Ramlogan S, Raman V, Sweet J (2014) A comparison of two forms of teaching instruction: video vs. live lecture for education in clinical periodontology. Eur J Dent Educ 18(1): 31-38.

5. Viswasom AA, Jobby A (2017) Effectiveness of Video Demonstration over Conventional Methods in Teaching Osteology in Anatomy. J Clin Diagn Res 11(2): JC09-JC11.

6. Smith W, Rafeek R, Marchan S, Paryag A (2012) The use of video-clips as a teaching aide. Eur J Dent Educ 16(2): 91-96.

7. Aragon CE, Zibrowski EM (2008) Does exposure to a procedural video enhance preclinical dental student performance in fixed prosthodontics? J Dent Educ 72(1): 67-71.

8. Chi DL, Pickrell JE, Riedy CA (2014) Student learning outcomes associated with video vs. paper cases in a public health dentistry course. J Dent Educ 78(1): 24-30.

9. McAndrew M, Johnston AE (2012) The role of social media in dental education. J Dent Educ 76(11): 1474-1481.

10. Avner Caspi, Paul Gorsky, Meira Privman (2005) Viewing comprehension: Students' learning preferences and strategies when studying from video. Instructional Science 33(1): 31-47. 